\title{
Synergistic Effects of Long-Term Antioxidant Diet and Behavioral Enrichment on $\beta$-Amyloid Load and Non-Amyloidogenic Processing in Aged Canines
}

\author{
Viorela Pop, ${ }^{1,2}$ Elizabeth Head, ${ }^{1,3}$ Mary-Ann Hill, ${ }^{1,3}$ Dan Gillen, ${ }^{1}$ Nicole C. Berchtold, ${ }^{1}$ Bruce A. Muggenburg, ${ }^{4}$ \\ Norton W. Milgram, ${ }^{5}$ M. Paul Murphy, ${ }^{6}$ and Carl W. Cotman ${ }^{1,2,3}$ \\ ${ }^{1}$ Institute for Brain Aging and Dementia and Departments of ${ }^{2}$ Neurobiology and Behavior and ${ }^{3}$ Neurology, University of California, Irvine, Irvine, California \\ 92697, ${ }^{4}$ Lovelace Respiratory Research Institute, Albuquerque, New Mexico, 87185, ${ }^{5}$ Division of Life Sciences, University of Toronto, Toronto, Ontario, \\ Canada M5S 1A1, and ${ }^{\circ}$ Department of Molecular and Cellular Biochemistry, Sanders-Brown Center on Aging, University of Kentucky, Lexington, Kentucky \\ 40536
}

A long-term intervention ( 2.69 years) with an antioxidant diet, behavioral enrichment, or the combined treatment preserved and improved cognitive function in aged canines. Although each intervention alone provided cognitive benefits, the combination treatment was additive. We evaluate the hypothesis that antioxidants, enrichment, or the combination intervention reduces age-related $\beta$-amyloid $(\mathrm{A} \beta)$ neuropathology, as one mechanism mediating observed functional improvements. Measures assessed were $\mathrm{A} \beta$ neuropathology in plaques, biochemically extractable $\mathrm{A} \beta_{40}$ and $\mathrm{A} \beta_{42}$ species, soluble oligomeric forms of $\mathrm{A} \beta$, and various proteins in the $\beta$-amyloid precursor protein (APP) processing pathway. The strongest and most consistent effects on A $\beta$ pathology were observed in animals receiving the combined antioxidant and enrichment treatment. Specifically, $\mathrm{A} \beta$ plaque load was significantly decreased in several brain regions, soluble $\mathrm{A} \beta_{42}$ was decreased selectively in the frontal cortex, and a trend for lower $\mathrm{A} \beta$ oligomer levels was found in the parietal cortex. Reductions in A $\beta$ may be related to shifted APP processing toward the non-amyloidogenic pathway, because $\alpha$-secretase enzymatic activity was increased in the absence of changes in $\beta$-secretase activity. Although enrichment alone had no significant effects on $\mathrm{A} \beta$, reduced $\mathrm{A} \beta$ load and plaque maturation occurred in animals receiving antioxidants as a component of treatment. $\mathrm{A} \beta$ measures did not correlate with cognitive performance on any of the six tasks assessed, suggesting that modulation of $A \beta$ alone may be a relatively minor mechanism mediating cognitive benefits of the interventions. Overall, the data indicate that multidomain treatments may be a valuable intervention strategy to reduce neuropathology and improve cognitive function in humans.

\section{Introduction}

Increasing evidence from human studies suggests that dietary and environmental interventions provide cognitive benefits and improve brain health, particularly in aged populations. For example, age-related cognitive decline was lessened by increased physical activity (Erickson and Kramer, 2009) or an "enriched environment" such as provided by cognitive training (Willis et al., 2006). Similarly, various dietary interventions rich in antioxidants may slow age-related cognitive decline and reduce the risk of Alzheimer's disease (AD) (Gray et al., 2003; Zandi et al., 2004;

Received Dec. 15, 2009; revised May 6, 2010; accepted June 1, 2010.

This work was supported by National Institutes of Health/National Institute on Aging Grants AG12694 and AG17066 and U.S. Department of the Army Contract DAMD17-98-1-8622. We thank the following people: Mihaela Nistor and Floyd Sarsoza for immunohistochemistry, Dr. Kim Green for ELISA, Drs. Paul Adlard and Wayne Poon for enzyme activity assays, and Dr. Lori-Ann Christie for manuscripts edits.

Correspondence should be addressed to Dr. Carl W. Cotman, Institute for Brain Aging and Dementia, Department of Neurobiology and Behavior, 1226 Gillespie Neuroscience Research Facility, University of California, Irvine, Irvine, CA 92697-4540. E-mail: cwcotman@uci.edu.

V. Pop's present address: Department of Pediatrics, Loma Linda University, Loma Linda, CA 92350.

E. Head's present address: Department of Molecular and Biomedical Pharmacology, Sanders-Brown Center on Aging, University of Kentucky, Lexington, KY 40536

DOI:10.1523/JNEUROSCI.6194-09.2010

Copyright $\odot 2010$ the authors $\quad 0270-6474 / 10 / 309831-09 \$ 15.00 / 0$
Dai et al., 2006). Studies in animal models provide several advantages over human studies in that precise dietary and behavioral protocols can be maintained over an extended time period, and effects on both cognitive function as well as underlying brain mechanisms can be assessed. Aged canines provide a valuable model for investigating mechanisms that underlie cognitive impairment. Like humans, aged beagles undergo cognitive decline in multiple cognitive domains that correlate with neuropathological changes (Cummings et al., 1996; Head et al., 1998, 2000). In parallel, aged beagles naturally accumulate several types of neuropathology that are consistent with human brain aging and $\mathrm{AD}$, including cortical atrophy (Tapp et al., 2004), neuron loss (Siwak-Tapp et al., 2008), declines in neurogenesis (Siwak-Tapp et al., 2007), reduced brain-derived neurotrophic factor (BDNF) (Fahnestock et al., 2010), increased oxidative damage (Head et al., 2002; Skoumalova et al., 2003), and increased $\beta$-amyloid (A $\beta$ ) accumulation (Cummings et al., 1996; Head et al., 1998, 2000).

Previously, we demonstrated that an antioxidant diet (AOX), behavioral enrichment (ENR), or the combination treatment improves cognition and prevents age-related cognitive decline in aged canines (Cotman et al., 2002; Milgram et al., 2002). Mechanisms identified include the improved capacity of the brain to 
counteract oxidative stress (Opii et al., 2008), improved mitochondrial function (Head et al., 2009), reduced neuron loss (Siwak-Tapp et al., 2007, 2008), and increased availability of growth factors such as BDNF (Fahnestock et al., 2010). The combination of AOXs and ENR consistently produced greater benefits to cognition and neurobiological outcome measures than either treatment alone.

In this study, we hypothesized that AOX, ENR, or the combined treatment may reduce $A \beta$ neuropathology in the canine brain. Previous studies have demonstrated that $\mathrm{A} \beta$ is reduced and cognition improved in transgenic $\mathrm{AD}$ mice by exposure to exercise (Adlard et al., 2005), ENR (Lazarov et al., 2005; Ambree et al., 2006; Costa et al., 2007), and select dietary compounds (Frautschy et al., 2001; Lim et al., 2001; Wang et al., 2008). However, other studies in transgenic AD mice have demonstrated improved cognition with ENR despite increased $\mathrm{A} \beta$ pathology (Jankowsky et al., 2005) and improved cognition in transgenic $\mathrm{AD}$ mice with $\mathrm{AOX}$ dietary supplementation without an affect on A $\beta$ (Joseph et al., 2003; Sung et al., 2004; Quinn et al., 2007). Thus, the relationship between improved cognitive function and reductions in $A \beta$ pathology is not clear-cut. To investigate whether cognitive improvements in the current study are paralleled by decreased $\mathrm{A} \beta$ pathology, we analyzed treatment effects on $\mathrm{A} \beta$ neuropathology and the amyloid precursor protein (APP) processing pathway in the aged canine.

\section{Materials and Methods}

Animals. Twenty-four beagles ranging in age 8.05-12.35 years at the start of the study (mean \pm SEM, $10.69 \pm 0.25$ years) were obtained from Lovelace Respiratory Research Institute (Albuquerque, NM) (supplemental Table 1, available at www.jneurosci.org as supplemental material). Animals were bred and maintained in the same environment, and all had documented dates of birth and comprehensive medical histories. All study dogs underwent extensive baseline cognitive testing as described previously (Milgram et al., 2002). Animals were subsequently ranked based on cognitive test scores and assigned to one of the following four treatment conditions: CC, control environment/control diet; EC, behavioral enrichment/control diet; CA, control environment/antioxidant diet; EA, behavioral enrichment/antioxidant diet. All animals, regardless of treatment condition, were evaluated annually on tests of visuospatial memory (Chan et al., 2002), object recognition memory (Callahan et al., 2000), and either size discrimination and reversal learning (Tapp et al., 2003) or black/white discrimination and reversal on consecutive years (Milgram et al., 2005). Cognitive results have been published for these animals (Cotman et al., 2002; Milgram et al., 2002). At the time the animals were killed, of the 24 aged animals that began the study, 23 dogs had received the intervention for $>2$ years (mean \pm SEM, $2.69 \pm 0.04$ years) and ranged in age from 10.71 to 15.01 years (mean \pm SEM, $13.31 \pm 0.26$ years), with one animal not completing the baseline phase of the study (supplemental Table 1, available at www.jneurosci.org as supplemental material). All research was conducted in accordance with approved Institutional Animal Care and Use Committee protocols.

Diet treatment. The control and AOX test diets were formulated to meet the nutrient profile recommendations for adult dogs from the American Association of Feed Control Officials (1999). Control and test diets were identical in composition, other than inclusion of a broadbased cellular AOX and mitochondrial cofactor supplementation in the AOX test diet (supplemental Table 2, available at www.jneurosci.org as supplemental material). The control and test diet had the following differences in formulation on an as-fed basis, respectively: DL- $\alpha$-tocopherol acetate (120 vs $1050 \mathrm{ppm})$, ascorbic acid as Stay-C (30 vs $80 \mathrm{ppm}$ ), acetyl-L-carnitine (20 vs $260 \mathrm{ppm}$ ), and DL- $\alpha$-lipoic acid ( $20 \mathrm{vs} 128 \mathrm{ppm}$ ). Based on an average weight of $10 \mathrm{~kg} / \mathrm{animal}$, the daily doses for each compound were $800 \mathrm{IU}$ or $210 \mathrm{mg} / \mathrm{d}\left(21 \mathrm{mg} \cdot \mathrm{kg}^{-1} \cdot \mathrm{d}^{-1}\right)$ of vitamin E, $16 \mathrm{mg} / \mathrm{d}$ $\left(1.6 \mathrm{mg} \cdot \mathrm{kg}^{-1} \cdot \mathrm{d}^{-1}\right)$ of vitamin C, $52 \mathrm{mg} / \mathrm{d}\left(5.2 \mathrm{mg} \cdot \mathrm{kg}^{-1} \cdot \mathrm{d}^{-1}\right)$ of acetylL-carnitine, and $26 \mathrm{mg} / \mathrm{d}\left(2.6 \mathrm{mg} \cdot \mathrm{kg}^{-1} \cdot \mathrm{d}^{-1}\right)$ of lipoic acid (supplemental
Table 2, available at www.jneurosci.org as supplemental material). The AOX diet used compounds and doses that have shown some efficacy in epidemiological studies. However, human trials have often used much higher doses than those used in the current study, with $\mathrm{AD}$ patients receiving acetyl-Lcarnitine at either $1 \mathrm{~g} / \mathrm{d}\left(14.3-16.6 \mathrm{mg} \cdot \mathrm{kg}^{-1} \cdot \mathrm{d}^{-1}\right.$ assuming average weight of 60-70 kg) (Bonavita, 1986) or $2 \mathrm{~g} / \mathrm{d}$ (Rai et al., 1990) and lipoic acid at dose levels up to $600 \mathrm{mg} / \mathrm{d}\left(8.5-10 \mathrm{mg} \cdot \mathrm{kg}^{-1} \cdot \mathrm{d}^{-1}\right.$ assuming average weight of 60-70 kg) (Hager et al., 2001). Fruits and vegetables were also incorporated at a 1:1 exchange ratio for corn, resulting in $1 \%$ inclusions of each of the following: spinach flakes, tomato pomace, grape pomace, carrot granules, and citrus pulp (supplemental Tables 2, 3, available at www.jneurosci.org as supplemental material).

Behavioral enrichment treatment. The behavioral ENR protocol consisted of four components: "social ENR" by housing animals in pairs, "environmental ENR" by providing novel play toys, "physical ENR" by providing two 20-min outdoor walks per week, and "cognitive ENR" through continuous cognitive testing consisting of $20-30 \mathrm{~min} / \mathrm{d}$. The cognitive ENR consisted of a landmark discrimination task, an oddity discrimination task (Milgram et al., 2002), and size concept learning (Tapp et al., 2003) as described previously (Cotman et al., 2002; Milgram et al., 2002).

Brain tissue. Twenty minutes before induction of general anesthesia, animals were sedated by subcutaneous injection with $0.2 \mathrm{mg} / \mathrm{kg}$ acepromazine. Subsequently, surgery-level general anesthesia was induced by inhalation with $5 \%$ isoflurane and animals were exsanguinated. The brain was removed and sectioned midsagitally, with the entire left hemisphere immediately placed in $4 \%$ paraformaldehyde for $48-72 \mathrm{~h}$ at $4^{\circ} \mathrm{C}$ before long-term storage in PBS with $0.05 \%$ sodium azide at $4^{\circ} \mathrm{C}$. The remaining right hemisphere was sectioned coronally (1-cm-thick sections) and flash frozen at $-80^{\circ} \mathrm{C}$. The dissection procedure was completed within $20 \mathrm{~min}$. The postmortem interval for all animals was 35-45 min.

$A \beta$ immunohistochemistry and quantification. Following previously published protocols (Head et al., 2008), tissue from the left hemisphere was sectioned at $40 \mu \mathrm{m}$ by Neuroscience Associates, followed by immunohistochemical processing. Briefly, free-floating sections containing the prefrontal, parietal, cingulate, entorhinal, and occipital cortices were pretreated with $90 \%$ formic acid, and $\mathrm{A} \beta$ plaques were detected with anti-A $\beta_{1-17}$ (mouse monoclonal 6E10 antibody, 1:5000; Signet Laboratories) and visualized with DAB (Vector Laboratories). Control experiments in which primary or secondary antibody was omitted resulted in negative staining. The procedure for quantifying $A \beta$ loads has been reported previously (Head et al., 2000). Briefly, 10 images were captured using a $20 \times$ objective in each brain region, and the area occupied by $\mathrm{A} \beta$ was quantified using grayscale thresholding (NIH Image) to obtain "A $\beta$ loads." Results were confirmed with an additional set of sections at least $200 \mu \mathrm{m}$ away.

Maturation gradient of $A \beta$ deposition ( $A \beta$ type). $\mathrm{A} \beta$ deposition in the canine frontal cortex is a progressive age-related process beginning with diffuse deposits in the deep cortical layers, followed by the development of deposits in outer cortical layers. To assess the severity of $A \beta$ pathology across treatment groups, we characterized $\mathrm{A} \beta$ maturation patterns in the same brain regions in which $\mathrm{A} \beta$ load was assessed, using methods described previously (Satou et al., 1997). Briefly, type 0 described regions without any $\mathrm{A} \beta$ plaque pathology; type 1 was characterized by small, faint, round $\mathrm{A} \beta$ deposits ( $<180 \mu \mathrm{m}$ in diameter), usually in deep cortical layers V and VI; type 2 were diffuse, cloud-like deposits that often fused together in the deep layers and occasionally spread to the superficial layers; type 3 had both diffuse deposits like those of type 2 in deep layers and dense, round plaques $(<120 \mu \mathrm{m}$ but sometimes over $200 \mu \mathrm{m})$ in superficial layers; and type 4 consisted solely of dense, round plaques throughout all layers of cortex. Sections were analyzed at several magnifications as needed for clarity and then assigned the correct type. All cases with $A \beta$ type 0,1 , or 2 were considered "early-stage" pathology, whereas all cases with $\mathrm{A} \beta$ type 3 or 4 contained plaques in the superficial layers and were considered "late-stage" pathology.

$A \beta$ ELISA. To detect differences among treatment groups in the prefrontal, parietal, temporal, and occipital cortices, we used previously published methods (Head et al., 2008). Briefly, frozen cortical samples were sequentially extracted in radioimmunoprecipitation assay (RIPA) 
buffer [pH 8, 50 mm Tris- $\mathrm{HCl}, 150 \mathrm{~mm} \mathrm{NaCl}, 0.5 \%$ deoxycholate, $0.1 \%$ SDS, $1 \%$ Triton X-100, and protease inhibitor cocktail (MP Biomedicals)] to obtain a soluble RIPA fraction and a RIPA pellet, which was resuspended in a $70 \%$ formic acid buffer (FA) to measure insoluble $\mathrm{A} \beta$. All FA samples were neutralized in neutralization buffer, and RIPA and FA preparations were run in triplicate on ELISA plates coated with a monoclonal anti-A $\beta_{1-16}$ antibody (kindly provided by Dr. William Van Nostrand, Stony Brook University, Stony Brook, NY). Detection was by monoclonal HRP-conjugated antibodies anti-A $\beta_{x-40}$ (MM32-13.1.1) or anti-A $\beta_{x-42}$ (MM40-21.3.1) (both antibodies kindly provided by Dr. Christopher Eckman, Mayo Clinic Jacksonville, Jacksonville, FA) (Kukar et al., 2005; McGowan et al., 2005). For standards, dilutions of $A \beta_{1-40}$ and $\mathrm{A} \beta_{1-42}$ peptides (Bachem California) were used after a pretreatment with hexafluoroisopropanol to prevent fibril formation. The inclusion of a series of controls to test the absorbance of buffers, samples, and antibodies yielded negative results.

Western blot. Parietal cortex was used for analysis of A $\beta$ oligomer levels and proteins in the APP processing pathway [TACE (tumor necrosis factor- $\alpha$ converting enzyme), ADAM10 (a disintegrin and metalloprotease 10), and C-terminal fragments (CTFs)] because this region showed decreased $\mathrm{A} \beta$ plaque load in response to treatments. Protein levels of APP, insulin degrading enzyme (IDE), and neprilysin were quantified in the parietal, prefrontal, hippocampal, and occipital regions. For oligomer studies, pulverized tissue samples were extracted in PBS buffer (powder packet from Sigma-Aldrich) $\left[\mathrm{pH} 7.4,0.2 \% \mathrm{NaN}_{3}\right.$ with Complete Mini protease inhibitor (Roche Diagnostics)]. For all other proteins, frozen tissue was homogenized in RIPA buffer at $1 \mathrm{ml}$ buffer/150 mg pulverized tissue weight. All samples were centrifuged at $100,000 \times g$ for $1 \mathrm{~h}$ at $4^{\circ} \mathrm{C}$, and soluble fractions were recovered and brought to an equal protein concentration by BCA (Pierce Biotechnology). For the detection of the $56 \mathrm{kDa} A \beta$ aggregate, $A \beta$ was immunoprecipitated from soluble PBS samples by overnight incubation with Protein A/G PLUSAgarose bead complex (Santa Cruz Biotechnology) and $5 \mu \mathrm{l}$ of the anti-A $\beta$ 6E10 antibody (mouse monoclonal for $\mathrm{A} \beta_{1-17}$; Covance). Unbound proteins were removed by washing with PBS buffer, and samples were centrifuged at $2500 \mathrm{rpm}$ for $5 \mathrm{~min}$ at $4^{\circ} \mathrm{C}$ to pellet the bead-antibody-protein complex. Loading buffer (2.5 mm Tris, pH 6.8, 2\% SDS, $0.007 \%$ bromophenol blue, $4 \% \beta$-mercaptoethanol, and $10 \%$ glycerol) was added to each sample, followed by boiling at $100^{\circ} \mathrm{C}$ for $5 \mathrm{~min}$. For Western blots, equal protein amounts were loaded for each sample on 4-20\% Tris-HCl Criterion gels (Bio-Rad), followed by transfer to sequiblot polyvinylidene difluoride membranes (Bio-Rad). For the oligomer studies, incubations were in Tris-buffered saline with $0.01 \%$ Tween 20 (TTBS), specifically using 3\% BSA/TTBS for all blocking and antibody incubations with $\beta$-actin (mouse, 1:5000; Abcam) and A11 antibodies (rabbit, 1:1000; Millipore Bioscience Research Reagents) (Kayed et al., 2003). For other protein analyses, incubations were in 5\% milk/TTBS. The antibodies used in Western blots were $\beta$-actin (rabbit, 1:5000; Abcam), glyceraldehyde 3-phosphate dehydrogenase (rabbit, 1:10,000; Millipore Bioscience Research Reagents), the N-terminal anti-A $\beta$ antibody $6 \mathrm{E} 10$ for APP (mouse, 1:5000; Signet Laboratories), the C-terminal anti-A $\beta$ antibody CT2 20 for full-length APP and CTF $\alpha$ and CTF $\beta$ (rabbit, 1:2000, raised against the C-terminal 20 aa of APP), antibodies to clearance enzymes IDE (mouse, 1:250; Covance) and neprilysin (rabbit, 1:50; Abcam), and an antibody to the precursor and mature form of the $\alpha$-secretase ( $\alpha$ SEC) enzyme TACE/ADAM17 (rabbit, 1:2000; Millipore Bioscience Research Reagents) or ADAM10 (rabbit, 1:500; Millipore Bioscience Research Reagents). Secondary antibodies were HRP-conjugated IgG anti-mouse (goat anti-mouse, 1:5000; Bio-Rad) or anti-rabbit (goat anti-rabbit, 1:10,000; Bio-Rad or Rockland Immunochemicals) as needed. Supersignal Chemiluminescent Substrate (Pierce Biotechnology) was used to visualize HRP activity on Hyperfilm ECL (GE Healthcare). The omission of primary antibody resulted in negative staining. Immunoblots were quantified using NIH Image J software, with optical density (OD) measures adjusted for individual $\beta$-actin OD levels.

$\alpha$ and $\beta$-secretase activity assays. These protocols have been published previously (Nistor et al., 2007). Briefly, frozen tissue was prepared according to protocols provided by the commercial supplier of the Secretase Activity kits (R \& D Systems). A total of $125 \mu \mathrm{g}$ of protein $(2.5 \mu \mathrm{g} / \mu \mathrm{l}$ in $50 \mu \mathrm{l}$ of total per well, OD read at $2 \mathrm{~h}$ ) was used for $\alpha \mathrm{SEC}$, and a total of $7.5 \mu \mathrm{g}$ of protein $(0.15 \mu \mathrm{g} / \mu \mathrm{l}$ in $50 \mu \mathrm{l}$ total per well, OD read at $30 \mathrm{~min})$ was used for the $\beta$ SEC assay. All samples were run in triplicate, and assays were replicated to confirm results.

Statistical analyses. To preclude bias, all data were collected while blind with respect to the experimental conditions. All statistical analyses were performed using SPSS for Windows, SYSTAT, or SAS, and graphs were produced using SigmaPlot. Generalized estimating equations (Zeger and Liang, 1986) and ANOVAs were used to compare mean A $\beta$ across treatment groups. Post hoc analyses considered the main effect of the AOX diet (comparing the $\mathrm{CC}+\mathrm{EC}$ groups vs the $\mathrm{CA}+\mathrm{EA}$ groups) and the behavioral ENR (comparing the CC+CA groups vs the $\mathrm{EC}+\mathrm{EA}$ groups). In data measures in which normality and variance assumptions were violated and not rectifiable by converting raw data to $\log 10$ scores, group differences were assessed according to the nonparametric Kruskal-Wallis analysis for multiple samples and the Mann-Whitney $U$ analysis for two independent samples. Correlations were assessed using the Pearson's coefficient or Spearman's rank nonparametric statistic as needed.

\section{Results}

To define the effects of AOX, ENR, or the combined intervention on $\mathrm{A} \beta$ pathology and $\mathrm{A} \beta$ processing in the canine brain, we analyzed treatment effects on extracellular $A \beta$ plaque load, levels of biochemically extractable $\mathrm{A} \beta_{40}$ and $\mathrm{A} \beta_{42}$ species, soluble oligomeric forms of $\mathrm{A} \beta$, and the APP processing pathway.

\section{Treatment effects on extracellular plaque pathology}

$\mathrm{A} \beta$ plaque immunostaining with the $6 \mathrm{E} 10$ antibody was quantified in the prefrontal, cingulate, parietal, entorhinal, and occipital cortices, revealing a differential treatment and brain region effect (Fig. 1). When all brain regions were considered together, $\mathrm{A} \beta$ plaque load was significantly reduced in the combined EA treatment group to $19 \%$ of untreated control (CC) levels $(p=0.01)$, whereas AOX treatment alone reduced $\mathrm{A} \beta$ plaque load in the $\mathrm{CA}$ group to $41 \%$ of untreated control (CC) levels ( $p=0.084$ ) (Fig. $1 A)$. In individual brain regions, the EA treatment group reduced $\mathrm{A} \beta$ plaque load to $18 \%$ of control (CC) levels in the cingulate cortex $(p=0.021)$, to $13 \%$ of control (CC) levels in the parietal cortex $(p=0.093)$, and to $10 \%$ of control (CC) levels in the entorhinal cortex $(p=0.077)$ (Fig. $1 B)$. Representative images from the parietal and entorhinal cortex are shown in Figure 1, $C$ and $D$, respectively.

Because the EA treatment group showed the largest overall effect on reducing A $\beta$ plaque load, treatment groups were pooled according to AOX diet or ENR condition to determine the possible relative contributions of each intervention strategy. Thus, the pooled AOX analysis consisted of control diet groups $(\mathrm{CC}+\mathrm{EC})$ compared with the AOX diet groups (CA+EA), whereas the pooled ENR analysis compared the control environment groups $(\mathrm{CC}+\mathrm{CA})$ versus the behavioral enrichment groups $(\mathrm{EC}+\mathrm{EA})$. Significantly lower $\mathrm{A} \beta$ load was detected in animals receiving the AOX diet (Fig. $2 A, B$ ) but not in animals receiving ENR treatment (Fig. 2C,D). The pooled AOX groups showed significantly lower $\mathrm{A} \beta$ load in the total brain analysis $(p=0.004)$ (Fig. $2 A)$, as well as in the cingulate cortex $(p=0.032)$ and the parietal cortex $(p=0.043)$ (Fig. $2 B)$. These data indicate that the reduction in $\mathrm{A} \beta$ plaques is stronger in animals receiving the $\mathrm{AOX}$ diet as a component of treatment than in animals receiving ENR as a component of treatment.

Because the duration of treatment spanned an extensive time period (2.69 years), we hypothesized that the treatment effects may reflect a change in the maturation pattern of $\mathrm{A} \beta$ accumulation. With age, $A \beta$ accumulates in a stereotypical laminar pattern within the cortex, reflecting a maturation gradient with early- 
stage deposits in the deep layers and latestage deposits occupying more superficial layers (Satou et al., 1997) (Fig. 3A). To determine whether AOX or ENR conditions influence plaque maturation, the percentage of animals exhibiting either early-stage or late-stage $\mathrm{A} \beta$ plaque pathology was calculated in the pooled AOX or ENR groups. Fewer late-stage deposits were observed in the prefrontal, cingulate, parietal, and entorhinal cortices in animals receiving the AOX diet as a component of treatment (Fig. 3B). In contrast, no consistent difference in early-stage and late-stage plaque pathology was observed in groups receiving ENR as a component of treatment $(p>0.05)$ (data not shown). These results suggest that the AOX diet may slow the progression of $A \beta$ accumulation within individual brain regions.

\section{Treatment effects on $\mathrm{A} \boldsymbol{\beta}_{40}, \mathrm{~A} \boldsymbol{\beta}_{42}$, and A $\boldsymbol{\beta}$ oligomers}

To determine whether the different interventions affected amyloid species and assembly states, we assessed the levels of soluble and insoluble $\mathrm{A} \beta_{40}$ and $\mathrm{A} \beta_{42}$ species and levels of $\mathrm{A} \beta$ oligomers. Soluble and insoluble $A \beta_{40}$ or $A \beta_{42}$ species were measured by ELISA in the prefrontal, parietal, temporal, and occipital cortices (Fig. 4). Mean $\mathrm{A} \beta_{40}$ was lowest in groups receiving the combined intervention, with the largest observed difference occurring in the parietal region, but no significant differences in soluble $\mathrm{A} \beta_{40}$ (Fig. $4 A$ ) or insoluble $\mathrm{A} \beta_{40}$ (Fig. $4 B$ ) were detected in any brain region. Significantly lower levels of soluble $\mathrm{A} \beta_{42}$ were detected selectively in the prefrontal cortex of the EA group compared with CC controls $(p=0.032)$ (Fig. $4 C$ ), whereas no significant changes in insoluble $\mathrm{A} \beta_{42}$ were observed in any region (Fig. 4D). Soluble and insoluble $\mathrm{A} \beta_{42 / 40}$ ratios showed no significant differences between groups in any brain region ( $p>0.05)$ (data not shown).

We next assessed whether $\mathrm{A} \beta$ oligomers are present in the canine brain and whether oligomer levels were modulated by AOX, ENR, or the combination treatment. Oligomeric proteins were assayed in the parietal cortex, because this region showed marked reductions in A $\beta$ plaque load after treatment. An oligomeric protein migrating at $56 \mathrm{kDa}$ was detected (Fig. $5 A$ ) that appears similar to the oligomeric species reported previously in transgenic mouse models of AD. Quantification of the $56 \mathrm{kDa}$ band revealed an $\sim 50 \%$ reduction (nonsignificant trend) and reduced within-group variability selectively in the combination EA treatment group (Fig. 5B).

These results indicate that the AOX or ENR interventions alone had little effect on steady-state levels of $\mathrm{A} \beta_{40}$ and $\mathrm{A} \beta_{42}$ species and oligomeric assembly states. However, the combined EA treatment resulted in lower levels of soluble $A \beta_{42}$ in the pre-
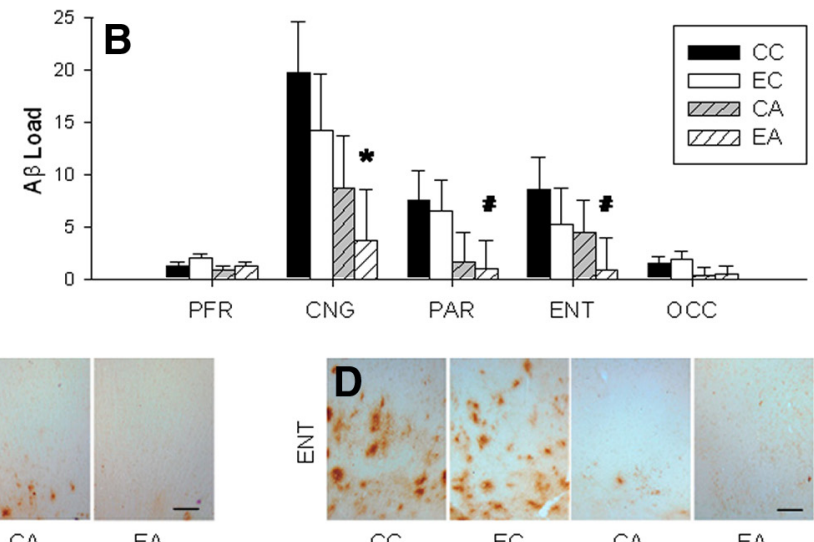

CA EA

$\mathrm{CC}$

EA

Figure 1. $A \beta$ load quantification across treatment groups. $A$, Mean $A \beta$ plaque accumulation across all brain regions shows ductions in the CA and EA groups receiving the antioxidant diet but not with behavioral enrichment alone. $\boldsymbol{B}, A \beta$ load is selectively decreased in the combination treatment EA group in the cingulate cortex, with trends for reduced levels in the parietal and entorhinal regions and no changes in the prefrontal or occipital cortex. Representative images are shown for each of the four treatment groups from the parietal $(\boldsymbol{C})$ and entorhinal $(\boldsymbol{D})$ cortices. PFR, Prefrontal; CNG, cingulate; PAR, parietal; ENT, entorhinal;
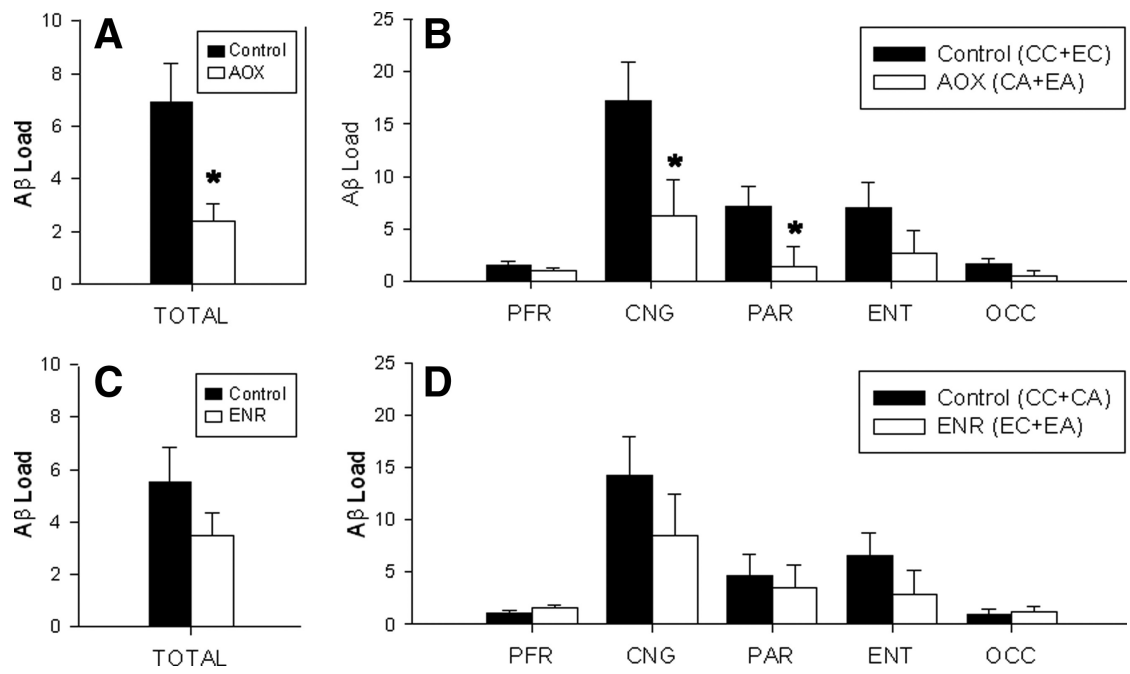

Figure 2. $A \beta$ load pooled according to diet or environment. $\boldsymbol{A}, \boldsymbol{B}$, When groups are separated according to diet, significantly lower $A \beta$ load is found in response to antioxidants in the total brain $(\boldsymbol{A})$ and individual brain region $(\boldsymbol{B})$ analysis in the cingulate and parietal cortex. $\boldsymbol{C}, \boldsymbol{D}$, When groups are separated according to environment, there are no significant changes in the total brain $(\boldsymbol{C})$ region $(\boldsymbol{B})$ analysis. PFR, Prefrontal; CNG, cingulate; PAR, parietal; ENT, entorhinal; OCC, occipital, Control in $\boldsymbol{A}, \boldsymbol{B}$ control diet groups $C($ and $E C$; Control in $C, D$, control environment groups $C C$ and $C A$; $A 0 X$, antioxidant diet groups $C A$ and EA; ENR, behavioral enrichment groups EC and EA. ${ }^{*} p<0.05$ from Control.

frontal cortex and a trend for reduced levels of the $56 \mathrm{kDa}$ oligomer in the parietal cortex.

\section{Changes in the APP processing pathway}

Together, the above data reveal decreased $\mathrm{A} \beta$ load in the canine brain, particularly in response to the combined EA treatment. Several mechanisms may underlie the reduction in $\mathrm{A} \beta$ load, including increased clearance by $\mathrm{A} \beta$ degrading enzymes, decreased availability of APP, or altered APP processing favoring the nonamyloidogenic pathway.

Levels of $\mathrm{A} \beta$ degrading enzymes and APP protein were analyzed by Western blot in the prefrontal, parietal, hippocampal, and occipital brain regions. The amyloid clearance proteins neprilysin and IDE remained steady across all treatment groups in all brain regions examined $(p>0.05)$ (data not shown). Similarly, there were no trends or significant differences in steady-state levels of total APP 
A

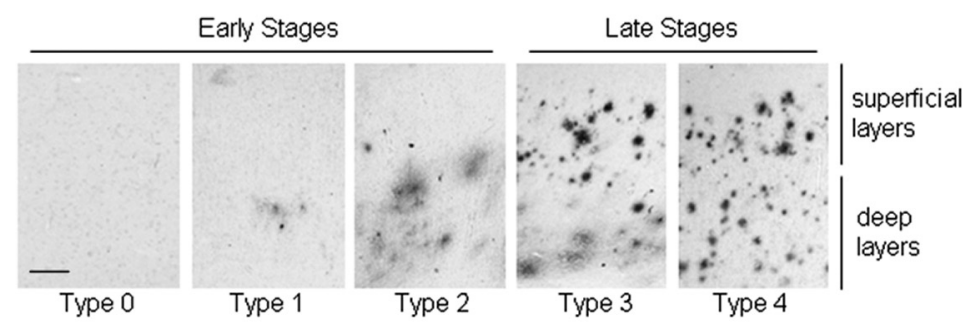

B

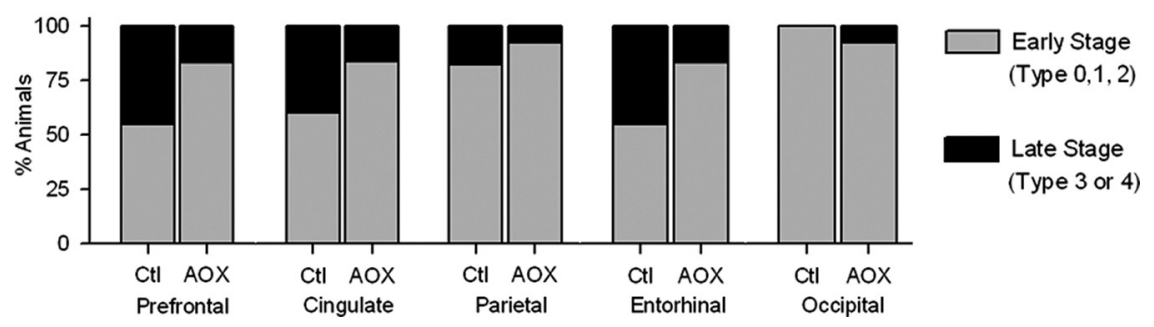

Figure 3. $A \beta$ plaque pathology. $A$, Sample images of the possible categorical $A \beta$ plaque types $0,1,2,3$, or 4 . Early-stage patterns (type 0,1 , or 2 ) reflect cortical involvement of the deep layers, whereas late stages (type 3 or 4 ) exhibit superficial layer involvement. $\boldsymbol{B}$, When groups are separated according to diet, animals receiving antioxidants have fewer late-stage deposits in the superficial cortical layers, including the prefrontal cortex, which did not show significant reductions in $A \beta$ load with treatments. Scale bar, $500 \mu \mathrm{m}$. Ctl, Control diet groups CC and EC; AOX, antioxidant diet groups CA and EA.
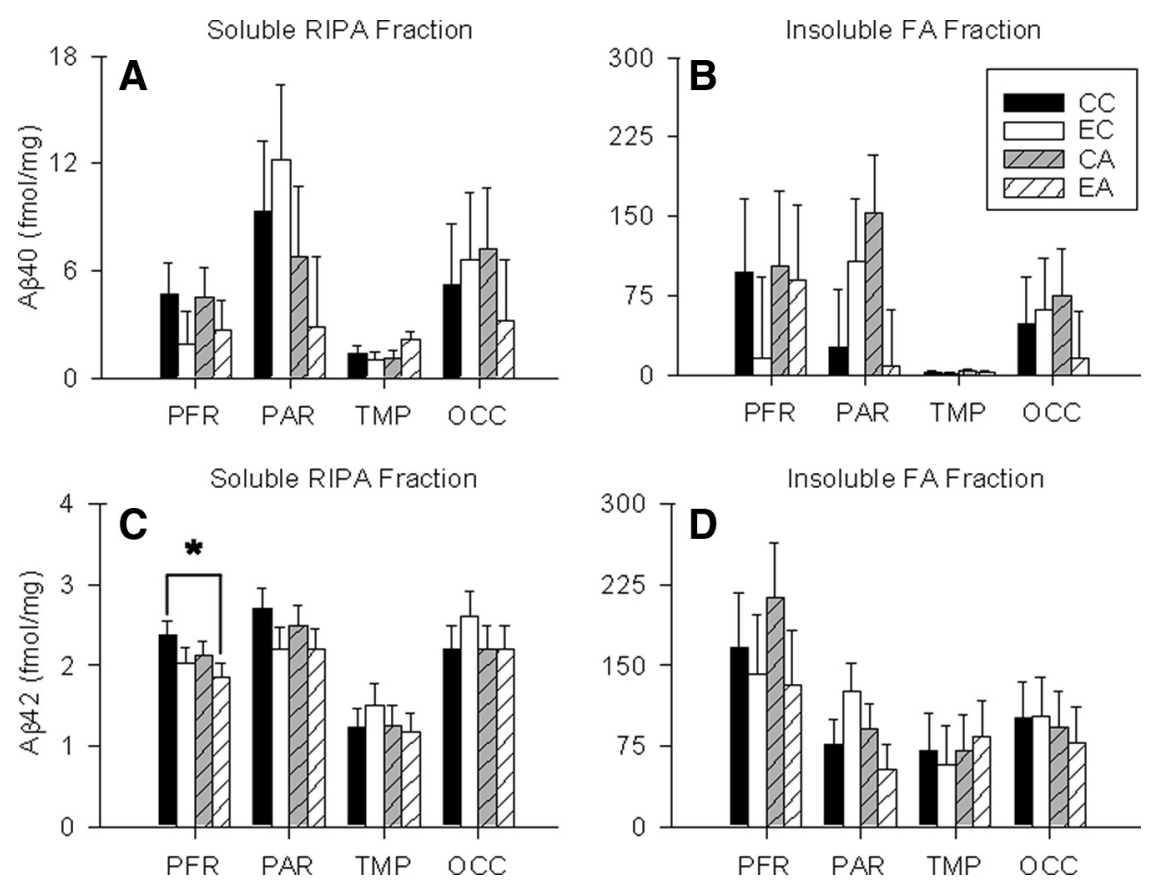

Figure 4. Soluble and insoluble $A \beta_{40}$ and $A \beta_{42}$ species by ELISA. In general, insoluble $A \beta$ was higher than soluble levels, and more $A \beta$ was detected in rostral versus caudal regions. There were no significant treatment effects in any brain regions in soluble $A \beta_{40}(A)$ or insoluble $A \beta_{40}(B)$. C, D, With the exception of significantly lower $A \beta_{42}$ in the $E A$ group of the frontal cortex, there were no significant changes in soluble $A \beta_{42}(C)$ or insoluble $A \beta_{42}(D)$. PFR, Prefrontal cortex; PAR, parietal cortex; TMP, temporal cortex; $0 C C$, occipital cortex. Error bars indicate group mean \pm SEM. ${ }^{*} p<0.05$ from CC controls.

protein levels in any brain regions, as assessed using both an $\mathrm{N}$-terminal or a C-terminal anti-A $\beta$ antibody $(p>0.05)$ (data not shown). These results indicate that neither increased availability of clearance proteins nor decreased availability of APP protein appear to contribute to the observed reductions in $\mathrm{A} \beta$ load after treatment with $\mathrm{AOX}, \mathrm{ENR}$, or the combined intervention.

Because $\mathrm{A} \beta$ accumulation likely reflects a balance between production and clearance mechanisms, we next examined whether differential APP cleavage might explain the reductions in $\mathrm{A} \beta$ attributable to enhanced non-amyloidogenic processing. Key proteins in the APP processing pathway were assessed by Western blot in the parietal cortex, a region in which $\mathrm{A} \beta$ was decreased in response to treatments. $\mathrm{CTF} \alpha$ and $\mathrm{CTF} \beta$, from APP cleavage by $\alpha$ SEC and $\beta$ SEC, respectively, remained unchanged with any treatment. Similarly, there were no significant differences in $\beta S E C$ enzymatic activity $(p>0.05)$ (data not shown). However, $\alpha$ SEC enzyme activity, indicative of non-amyloidogenic APP processing, was significantly increased in the combined EA treatment group $(20 \%, p<0.05)$ but not in the individual AOX or ENR treatment groups (Fig. $6 A$ ). $\beta$ SEC activity was unchanged in all treatment groups. To determine which $\alpha$ SEC protein might underlie increases in enzymatic activity, protein levels of the major $\alpha$ SEC candidates TACE and ADAM10 were quantified. TACE levels were not significantly altered among groups $(p>0.05)$ (data not shown), but levels of the precursor to ADAM10 showed a nonsignificant increase in groups receiving the $\mathrm{AOX}$ diet (CA and EA) but not enrichment alone (EC) (Fig. 6B,C). Protein levels of the mature form of ADAM10 remained unchanged.

Together, these results indicate that the treatment interventions do not alter levels of APP or two of the major clearance proteases, neprilysin and IDE. However, combined EA treatment appears to increase $\alpha$ SEC enzymatic activity, in the absence of a significant change in $\beta S E C$, suggesting a shift to the non-amyloidogenic pathway, consistent with the reductions in $\mathrm{A} \beta$ plaque deposition observed in the EA treatment group.

\section{Relationship of cognitive performance with measures of $A \boldsymbol{\beta}$ pathology}

We next assessed whether changes in $A \beta$ pathology correlated with the improved cognitive performance that was reported previously in these dogs in response to ENR, AOX, or the combination of the interventions. Six performance measures had been evaluated previously across all four groups of dogs: discrimination errors and discrimination reversal errors in year 2 of treatment, spatial memory phase 10 errors (years 2 and 3 of treatment), and black/white intensity discrimination errors and reversal errors (year 3 of treatment). Two-tailed Pearson's correlations were calculated for performance and the following variables for the 23 dogs: total $A \beta$ load across brain regions, $A \beta$ load in individual brain regions, levels of $\mathrm{A} \beta_{40}, \mathrm{~A} \beta_{42}$, oligomers, and $\alpha \mathrm{SEC}$ activity. No significant correlation or trend for a correlation was found between any cognitive measure and any measure of A $\beta$ pathology or APP processing. 


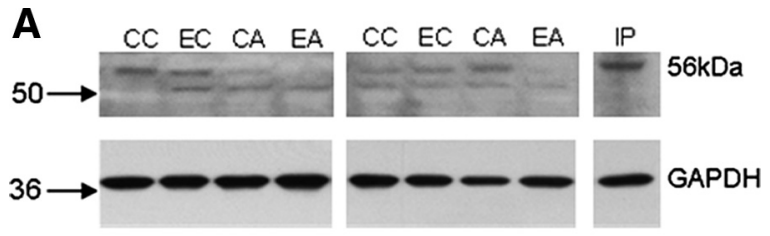

B

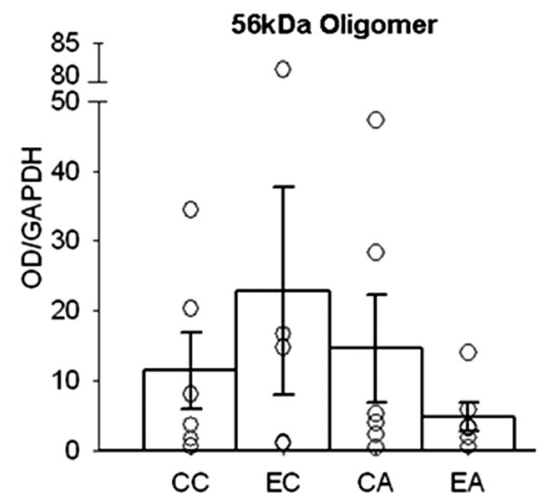

Figure 5. $A \beta$ oligomeric proteins. $A$, Representative samples from the canine parietal cortex show the anti-oligomer $\mathrm{A} 11$ antibody detecting the $A \beta$ oligomeric protein at $56 \mathrm{kDa}$. B, Lower levels and reduced variability of the $56 \mathrm{kDa}$ aggregate are seen in the combination treatment group EA despite a large amount of variability within the groups. IP, Immunoprecipitated canine sample with anti-A $\beta_{1-16} 6 \mathrm{E} 10$ antibody. Numbers on left in $A$ indicate kilodalton marker; GAPDH, glyceraldehyde-3-phosphate dehydrogenase.

For example, looking at $\mathrm{A} \beta$ load across brain regions and behavioral task performance in year 3 of treatment, Pearson's correlations were as follows: spatial memory performance $(r=0.198$, $p=0.366)$, black/white intensity discrimination errors $(r=$ $-0.096, p=0.662)$, and black/white intensity discrimination reversal errors $(r=-0.134, p=0.543)$. These results suggest that improvements in cognition in response to treatments were minimally related to changes in $\mathrm{A} \beta$ pathology.

\section{Discussion}

Previously, we have shown that a long-term intervention (2.69 years) with an AOX diet, behavioral ENR, or the combined EA treatment preserves and improves cognitive function in aged canines. Although each intervention alone provided benefits, the combination treatment had additive benefits for cognition (Cotman et al., 2002; Milgram et al., 2002). Here we evaluated the hypothesis that AOX and ENR interventions reduce age-related $\mathrm{A} \beta$ neuropathology as one mechanism that may contribute to the observed cognitive improvement.

\section{The combination of dietary AOXs and behavioral ENR interventions is optimal}

Overall, across the treatment groups, the strongest and most consistent effects on $\mathrm{A} \beta$ pathology were observed in canines receiving the combined EA intervention. After combined EA treatment, A $\beta$ load was significantly decreased in several brain regions, soluble $\mathrm{A} \beta_{42}$ was decreased selectively in the frontal cortex, and the $\mathrm{A} \beta 56$ $\mathrm{kDa}$ oligomer showed a trend for lower levels and reduced variability in the parietal cortex. The increase in $\alpha$ SEC activity, in the absence of changes in $\beta$ SEC activity, suggests that reductions in $\mathrm{A} \beta$ may be related to a shift in APP processing toward the nonamyloidogenic pathway. Previously, increased $\alpha$ SEC activity in the absence of changed $\beta$ - or $\gamma$-secretase activity has been linked to moderate decreases in $\mathrm{A} \beta_{40}$ and $\mathrm{A} \beta_{42}$ in calorie-restricted primates (Qin et al., 2006), suggesting that shifted processing to the non-amyloidogenic pathway may serve to reduce $A \beta$ in higher
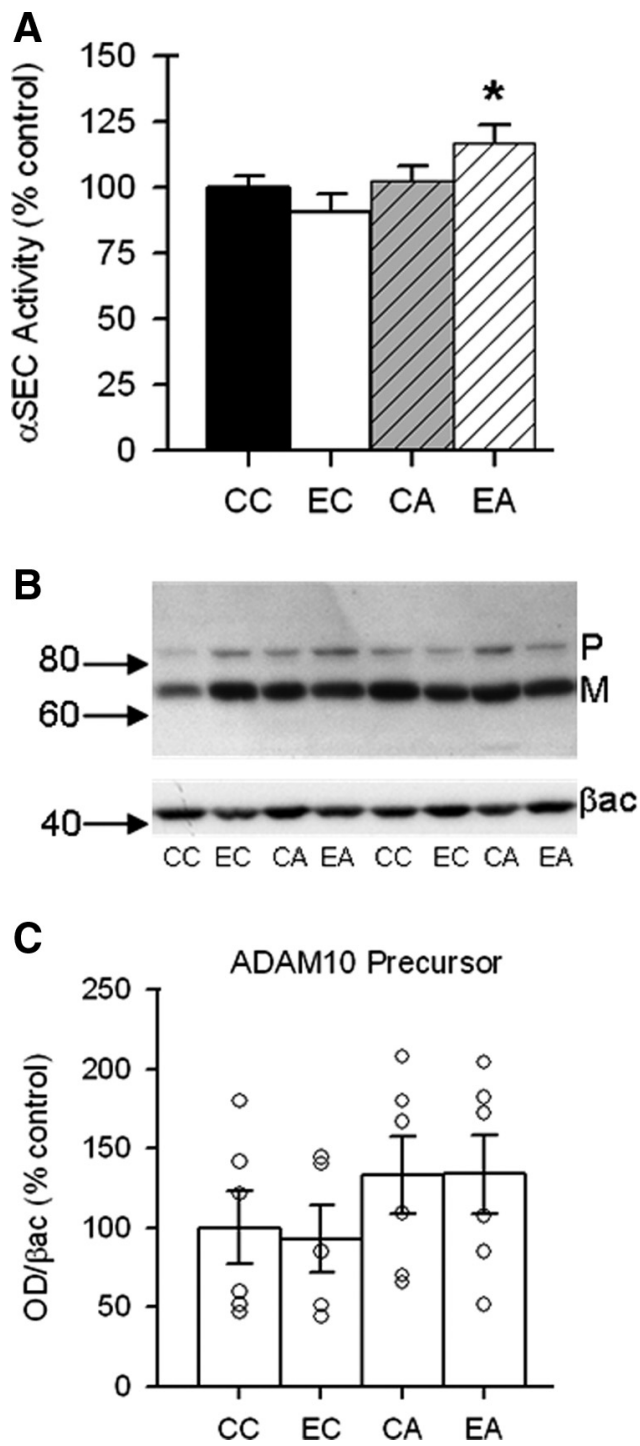

Figure 6. Non-amyloidogenic APP processing. $\boldsymbol{A}, \alpha$-Secretase activity is selectively increased in the parietal cortex of the combination EA group. $\boldsymbol{B}$, Representative samples show ADAM10 precursor and mature protein in the parietal cortex of canines. $C$, Quantification of proteins in $B$ shows a trend toward increased ADAM10 precursor levels in the CA and EA groups. $\beta a c, \beta$-Actin; $P$, ADAM10 precursor protein; M, ADAM10 mature protein. Error bars indicate group mean \pm SEM; circles indicate individual data points. ${ }^{*} p<0.05$ compared with CC and EC.

animal models. In addition, our findings are consistent with effects of other natural compounds that reduced $\mathrm{A} \beta$ and increased $\alpha$ SEC activity, such as Ginkgo biloba (Colciaghi et al., 2004) and green tea (Levites et al., 2003; Rezai-Zadeh et al., 2005; Obregon et al., 2006). The absence of a detectable increase in the CTF $\alpha$ fragment concomitant with the $20 \%$ increase in $\alpha$ SEC activity may reflect an effect on APP processing that is below detection or that the CTF $\alpha$ fragment is rapidly degraded.

To estimate the relative contribution of either AOX or ENR treatment to reductions in $\mathrm{A} \beta$ load, treatment groups were pooled according to the inclusion of AOX or ENR as a component of treatment. This analysis revealed significantly reduced $A \beta$ load when animals were pooled according to the presence of AOXs ( $\sim 50 \%$ reduction) but not when pooled according to ENR ( $\sim 20 \%$ reduction). Similarly, the pooled AOX groups (but not the ENR groups) exhibited more early-stage deposits and fewer late-stage deposits, indicating a slower $\mathrm{A} \beta$ plaque maturation and 
accumulation process. These data indicate that the reduction in $\mathrm{A} \beta$ plaques is stronger in animals that received the AOX diet as a component of treatment compared with ENR. Interestingly, the effect of the AOX intervention on reducing $A \beta$ load and maturation are enhanced when combined with ENR, resulting in a $80 \%$ reduction in amyloid plaque load, although ENR on its own had little effect.

The concept that combined dietary and behavioral interventions can have superior effects to either approach alone builds on previous literature. For example, in mice, the effects of voluntary exercise (a component of the ENR paradigm) was improved when exercise was combined with dietary administration of the plant flavonol epicatechin (van Praag et al., 2007). In addition, in rats, combining exercise with the $\omega$-3 fatty acid docosahexaenoic acid resulted in synergistic effects on improving cognition and enhancing synaptic plasticity in the BDNF pathway (Wu et al., 2008). Similarly, we demonstrate that combined dietary and behavioral interventions are more effective at reducing amyloid pathology than either intervention alone.

\section{Does $A \boldsymbol{\beta}$ accumulation influence cognitive decline in higher animal models?}

Our data indicate that the combination of AOX and ENR significantly reduced $A \beta$ load in the brain, with only modest effects on levels of soluble and insoluble $\mathrm{A} \beta$ species and assembly states. On one hand, the reduction in amyloid load in the absence of reductions in steady-state amyloid levels seems paradoxical. However, $\mathrm{A} \beta$ immunization, which decreases $\mathrm{A} \beta$ load, has been associated with unchanged or even increased steady-state $A \beta$ levels in humans (Patton et al., 2006). The observed reductions in $A \beta$ load and more immature plaque distribution with EA treatment may reflect a compartmentalization of amyloid such that, with reduced amyloid burden overall, fewer cellular elements are exposed to extracellular amyloid. The more immature plaque distribution pattern may further allow select brain regions to function in a more youthful state even with minimal changes in amyloid levels.

The importance of $\mathrm{A} \beta$ accumulation in driving cognitive decline in higher animal models of aging is under ongoing debate. It is well accepted that $A \beta$ impairs cognition in transgenic mouse models of $\mathrm{AD}$, but the case is less clear in higher animal models with a natural course of $A \beta$ accumulation. For example, in aged canines, although $\mathrm{A} \beta$ immunization substantially reduced $\mathrm{A} \beta$ plaque load and $\mathrm{A} \beta$ levels, cognitive performance was essentially unaffected, with the exception of some improvement and maintenance in executive function on a reversal learning task after a $2+$ year treatment (Head et al., 2008). By comparison, in aged canines given AOX and ENR treatments and administered the same cognitive tasks as immunized animals, there were robust cognitive improvements across multiple measures of learning and memory (Cotman et al., 2002; Milgram et al., 2002). Similar to the canine immunization results, in recent human clinical trials, immunization of $\mathrm{AD}$ patients reduced $\mathrm{A} \beta$ load but had only minor effects on cognitive improvement and did not slow disease progression (Gilman et al., 2005; Holmes et al., 2008; Kokjohn and Roher, 2009). This literature suggests that factors in addition to $A \beta$ neuropathology may be important determinants of cognitive performance and the rate of cognitive decline.

The modest effects of AOX, ENR, or the combination intervention on $\mathrm{A} \beta_{40}$ and $\mathrm{A} \beta_{42}$ levels in canines may provide insight into human brain aging. In humans, various lifestyle factors (e.g., education, social networks, and activity participation) can help build cognitive reserve, allowing the brain to tolerate more amy- loid pathology, and maintain intact cognitive function (Bennett et al., 2006; Roe et al., 2008a,b).

\section{Multiple mechanisms may underlie the cognitive benefits of AOX and ENR interventions}

Multiple mechanisms may ultimately determine the capacity of the AOX and ENR interventions to improve cognitive function. Several mechanisms have been identified, including improved capacity to counteract oxidative stress (Opii et al., 2008), improved mitochondrial function (Head et al., 2009), preserved neuron number (Siwak-Tapp et al., 2008), and increased availability of growth factors such as BDNF (Fahnestock et al., 2010). Interestingly, the combined EA treatment appears to have additive or synergistic effects on several neurobiological endpoints. The molecular endpoint showing the greatest effects of the interventions to date has been an improved capacity to counteract age-related oxidative damage (Opii et al., 2008). In canines, the AOX, ENR, or combined EA intervention reduced the extent of oxidative damage and improved the AOX reserve system, by decreasing levels of oxidative stress biomarkers and increasing activity of key enzymes involved in energy metabolism and regulation of oxidative stress [e.g., $\mathrm{Cu}-\mathrm{Zn}$ superoxide dismutase (SOD) and glutathione $S$-transferase (GST)] (Opii et al., 2008). The increases in SOD and GST enzymatic activity were positively correlated with improvements in cognitive performance (Opii et al., 2008). Similar to the correlation between oxidative enzymatic activity and cognitive performance, the extent of neurogenesis correlated with cognitive score across treatment groups, with the strongest relationship in the combined intervention (SiwakTapp et al., 2007). In contrast, changes in $\mathrm{A} \beta$ pathology observed in the current study did not correlate with improvements in cognitive performance based on the same cognitive tasks. This literature suggests that the AOX and ENR interventions may engage compensatory molecular mechanisms that build cognitive reserve, allowing the canine to maintain intact cognitive abilities despite the continued presence of $A \beta$ in the brain (Bennett et al., 2006; Roe et al., 2008a,b).

\section{Summary}

Our data adds to a growing body of knowledge that changes in cognitive function in higher animal models and humans are not consistently linked to changes in amyloid neuropathology. In this study, treatment of aged dogs with AOX, ENR, or the combined intervention strongly improved cognitive function, although amyloid pathology overall was only moderately reduced. Although $\mathrm{A} \beta$ load was decreased, particularly with the combined intervention, steady-state levels of $\mathrm{A} \beta_{40}$ and $\mathrm{A} \beta_{42}$ and oligomeric assembly states were only modestly reduced, despite a shift of APP processing to the non-amyloidogenic pathway. Recent data confirm that multiple mechanisms, perhaps in parallel with modest reductions in $\mathrm{A} \beta$, may contribute to the cognitive health and functional benefits provided by the interventions. Importantly, across all molecular mechanisms, including the $\mathrm{A} \beta$ pathway, the strongest effects consistently occurred in the combined EA treatment group, which also sustained the greatest cognitive benefits. These data suggest that multidomain treatments may be a valuable intervention strategy to reduce pathology and improve cognitive function in humans.

\section{References}

Adlard PA, Perreau VM, Pop V, Cotman CW (2005) Voluntary exercise decreases amyloid load in a transgenic model of Alzheimer's disease. J Neurosci 25:4217-4221. 
Ambree O, Leimer U, Herring A, Gortz N, Sachser N, Heneka MT, Paulus W, Keyvani K (2006) Reduction of amyloid angiopathy and Abeta plaque burden after enriched housing in TgCRND8 mice: involvement of multiple pathways. Am J Pathol 169:544-552.

Association of American Feed Control Officials (1999) Association of American Feed Control Officials, AAFCO dog and cat food nutrient profiles. West Lafayette, IN: Association of American Feed Control Officials.

Bennett DA, Schneider JA, Tang Y, Arnold SE, Wilson RS (2006) The effect of social networks on the relation between Alzheimer's disease pathology and level of cognitive function in old people: a longitudinal cohort study. Lancet Neurol 5:406-412.

Bonavita E (1986) Study of the efficacy and tolerability of L-acetylcarnitine therapy in the senile brain. Int J Clin Pharmacol Ther Toxicol 24:511-516.

Callahan H, Ikeda-Douglas C, Head E, Cotman CW, Milgram NW (2000) Development of a protocol for studying object recognition memory in the dog. Prog Neuropsychopharmacol Biol Psychiatry 24:693-707.

Chan AD, Nippak PM, Murphey H, Ikeda-Douglas CJ, Muggenburg B, Head E, Cotman CW, Milgram NW (2002) Visuospatial impairments in aged canines (Canis familiaris): the role of cognitive-behavioral flexibility. Behav Neurosci 116:443-454.

Colciaghi F, Borroni B, Zimmermann M, Bellone C, Longhi A, Padovani A, Cattabeni F, Christen Y, Di Luca M (2004) Amyloid precursor protein metabolism is regulated toward alpha-secretase pathway by Ginkgo biloba extracts. Neurobiol Dis 16:454-460.

Costa DA, Cracchiolo JR, Bachstetter AD, Hughes TF, Bales KR, Paul SM, Mervis RF, Arendash GW, Potter H (2007) Enrichment improves cognition in $\mathrm{AD}$ mice by amyloid-related and unrelated mechanisms. Neurobiol Aging 28:831-844.

Cotman CW, Head E, Muggenburg BA, Zicker S, Milgram NW (2002) Brain aging in the canine: a diet enriched in antioxidants reduces cognitive dysfunction. Neurobiol Aging 23:809-818.

Cummings BJ, Head E, Afagh AJ, Milgram NW, Cotman CW (1996) Betaamyloid accumulation correlates with cognitive dysfunction in the aged canine. Neurobiol Learn Mem 66:11-23.

Dai Q, Borenstein AR, Wu Y, Jackson JC, Larson EB (2006) Fruit and vegetable juices and Alzheimer's disease: the Kame Project. Am J Med 119:751-759.

Erickson KI, Kramer AF (2009) Aerobic exercise effects on cognitive and neural plasticity in older adults. Br J Sports Med 43:22-24.

Fahnestock M, Marchese M, Head E, Pop V, Milgram NW, Cotman CW (2010) BDNF increases with behavioural enrichment and an antioxidant diet in the aged dog. Neurobiol Aging. Advance online publication. Retrieved May 4, 2010. doi:10.1016/j.neurobiolaging.2010.03.019.

Hager K, Marahrens A, Kenklies M, Riederer P, Münch G (2001) Alphalipoic acid as a new treatment option for Azheimer type dementia. Arch Gerontol Geriatr 32:275-282.

Frautschy SA, Hu W, Kim P, Miller SA, Chu T, Harris-White ME, Cole GM (2001) Phenolic anti-inflammatory antioxidant reversal of Abetainduced cognitive deficits and neuropathology. Neurobiol Aging 22: 993-1005.

Gilman S, Koller M, Black RS, Jenkins L, Griffith SG, Fox NC, Eisner L, Kirby L, Rovira MB, Forette F, Orgogozo JM (2005) Clinical effects of Abeta immunization (AN1792) in patients with $\mathrm{AD}$ in an interrupted trial. Neurology 64:1553-1562.

Gray SL, Hanlon JT, Landerman LR, Artz M, Schmader KE, Fillenbaum GG (2003) Is antioxidant use protective of cognitive function in the community-dwelling elderly? Am J Geriatr Pharmacother 1:3-10.

Head E, Callahan H, Muggenburg BA, Cotman CW, Milgram NW (1998) Visual-discrimination learning ability and beta-amyloid accumulation in the dog. Neurobiol Aging 19:415-425.

Head E, McCleary R, Hahn FF, Milgram NW, Cotman CW (2000) Regionspecific age at onset of beta-amyloid in dogs. Neurobiol Aging 21:89-96.

Head E, Liu J, Hagen TM, Muggenburg BA, Milgram NW, Ames BN, Cotman CW (2002) Oxidative damage increases with age in a canine model of human brain aging. J Neurochem 82:375-381.

Head E, Pop V, Vasilevko V, Hill M, Saing T, Sarsoza F, Nistor M, Christie LA, Milton S, Glabe C, Barrett E, Cribbs D (2008) A two-year study with fibrillar $\beta$-amyloid $(A \beta)$ immunization in aged canines: effects on cognitive function and brain A $\beta$. J Neurosci 28:3555-3566.

Head E, Nukala VN, Fenoglio KA, Muggenburg BA, Cotman CW, Sullivan PG (2009) Effects of age, dietary, and behavioral enrichment on brain mitochondria in a canine model of human aging. Exp Neurol 220:171-176.
Holmes C, Boche D, Wilkinson D, Yadegarfar G, Hopkins V, Bayer A, Jones RW, Bullock R, Love S, Neal JW, Zotova E, Nicoll JA (2008) Long-term effects of Abeta42 immunisation in Alzheimer's disease: follow-up of a randomised, placebo-controlled phase I trial. Lancet 372:216-223.

Jankowsky JL, Melnikova T, Fadale DJ, Xu GM, Slunt HH, Gonzales V, Younkin LH, Younkin SG, Borchelt DR, Savonenko AV (2005) Environmental enrichment mitigates cognitive deficits in a mouse model of Alzheimer's disease. J Neurosci 25:5217-5224.

Joseph JA, Denisova NA, Arendash G, Gordon M, Diamond D, Shukitt-Hale B, Morgan D (2003) Blueberry supplementation enhances signaling and prevents behavioral deficits in an Alzheimer disease model. Nutr Neurosci 6:153-162.

Kayed R, Head E, Thompson JL, McIntire TM, Milton SC, Cotman CW, Glabe CG (2003) Common structure of soluble amyloid oligomers implies common mechanism of pathogenesis. Science 300:486-489.

Kokjohn TA, Roher AE (2009) Antibody responses, amyloid-beta peptide remnants and clinical effects of AN-1792 immunization in patients with $\mathrm{AD}$ in an interrupted trial. CNS Neurol Disord Drug Targets 8:88-97.

Kukar T, Murphy MP, Eriksen JL, Sagi SA, Weggen S, Smith TE, Ladd T, Khan MA, Kache R, Beard J, Dodson M, Merit S, Ozols VV, Anastasiadis PZ, Das P, Fauq A, Koo EH, Golde TE (2005) Diverse compounds mimic Alzheimer disease-causing mutations by augmenting Abeta42 production. Nat Med 11:545-550.

Lazarov O, Robinson J, Tang YP, Hairston IS, Korade-Mirnics Z, Lee VM, Hersh LB, Sapolsky RM, Mirnics K, Sisodia SS (2005) Environmental enrichment reduces Abeta levels and amyloid deposition in transgenic mice. Cell 120:701-713.

Levites Y, Amit T, Mandel S, Youdim MB (2003) Neuroprotection and neurorescue against Abeta toxicity and PKC-dependent release of nonamyloidogenic soluble precursor protein by green tea polyphenol (-)-epigallocatechin-3-gallate. FASEB J 17:952-954.

Lim GP, Chu T, Yang F, Beech W, Frautschy SA, Cole GM (2001) The curry spice curcumin reduces oxidative damage and amyloid pathology in an Alzheimer transgenic mouse. J Neurosci 21:8370-8377.

McGowan E, Pickford F, Kim J, Onstead L, Eriksen J, Yu C, Skipper L, Murphy MP, Beard J, Das P, Jansen K, Delucia M, Lin WL, Dolios G, Wang R, Eckman CB, Dickson DW, Hutton M, Hardy J, Golde T (2005) Abeta42 is essential for parenchymal and vascular amyloid deposition in mice. Neuron 47:191-199.

Milgram NW, Zicker SC, Head E, Muggenburg BA, Murphey H, IkedaDouglas CJ, Cotman CW (2002) Dietary enrichment counteracts ageassociated cognitive dysfunction in canines. Neurobiol Aging 23:737-745.

Milgram NW, Head E, Zicker SC, Ikeda-Douglas CJ, Murphey H, Muggenburg B, Siwak C, Tapp D, Cotman CW (2005) Learning ability in aged beagle dogs is preserved by behavioral enrichment and dietary fortification: a two-year longitudinal study. Neurobiol Aging 26:77-90.

Nistor M, Don M, Parekh M, Sarsoza F, Goodus M, Lopez GE, Kawas C, Leverenz J, Doran E, Lott IT, Hill M, Head E (2007) Alpha- and betasecretase activity as a function of age and beta-amyloid in Down syndrome and normal brain. Neurobiol Aging 28:1493-1506.

Obregon DF, Rezai-Zadeh K, Bai Y, Sun N, Hou H, Ehrhart J, Zeng J, Mori T, Arendash GW, Shytle D, Town T, Tan J (2006) ADAM10 activation is required for green tea (-)-epigallocatechin-3-gallate-induced alphasecretase cleavage of amyloid precursor protein. J Biol Chem 281: 16419-16427.

Opii WO, Joshi G, Head E, Milgram NW, Muggenburg BA, Klein JB, Pierce WM, Cotman CW, Butterfield DA (2008) Proteomic identification of brain proteins in the canine model of human aging following a long-term treatment with antioxidants and a program of behavioral enrichment: relevance to Alzheimer's disease. Neurobiol Aging 29:51-70.

Patton RL, Kalback WM, Esh CL, Kokjohn TA, Van Vickle GD, Luehrs DC, Kuo YM, Lopez J, Brune D, Ferrer I, Masliah E, Newel AJ, Beach TG, Castano EM, Roher AE (2006) Amyloid-beta peptide remnants in AN1792-immunized Alzheimer's disease patients: a biochemical analysis. Am J Pathol 169:1048-1063.

Qin W, Chachich M, Lane M, Roth G, Bryant M, de Cabo R, Ottinger MA, Mattison J, Ingram D, Gandy S, Pasinetti GM (2006) Calorie restriction attenuates Alzheimer's disease type brain amyloidosis in squirrel monkeys (Saimiri sciureus). J Alzheimers Dis 10:417-422.

Quinn JF, Bussiere JR, Hammond RS, Montine TJ, Henson E, Jones RE, Stackman RW Jr. (2007) Chronic dietary alpha-lipoic acid reduces defi- 
cits in hippocampal memory of aged Tg2576 mice. Neurobiol Aging 28:213-225.

Rai G, Wright G, Scott L, Beston B, Rest J, Exton-Smith AN (1990) Doubleblind, placebo controlled study of acetyl-L-carnitine in patients with Alzheimer's dementia. Curr Med Res Opin 11:638-647.

Rezai-Zadeh K, Shytle D, Sun N, Mori T, Hou H, Jeanniton D, Ehrhart J, Townsend K, Zeng J, Morgan D, Hardy J, Town T, Tan J (2005) Green tea epigallocatechin-3-gallate (EGCG) modulates amyloid precursor protein cleavage and reduces cerebral amyloidosis in Alzheimer transgenic mice. J Neurosci 25:8807-8814.

Roe CM, Xiong C, Miller JP, Cairns NJ, Morris JC (2008a) Interaction of neuritic plaques and education predicts dementia. Alzheimer Dis Assoc Disord 22:188-193.

Roe CM, Mintun MA, D’Angelo G, Xiong C, Grant EA, Morris JC (2008b) Alzheimer disease and cognitive reserve: variation of education effect with carbon 11-labeled Pittsburgh Compound B uptake. Arch Neurol 65:1467-1471.

Satou T, Cummings BJ, Head E, Nielson KA, Hahn FF, Milgram NW, Velazquez P, Cribbs DH, Tenner AJ, Cotman CW (1997) The progression of beta-amyloid deposition in the frontal cortex of the aged canine. Brain Res 774:35-43.

Siwak-Tapp CT, Head E, Muggenburg BA, Milgram NW, Cotman CW (2007) Neurogenesis decreases with age in the canine hippocampus and correlates with cognitive function. Neurobiol Learn Mem 88:249-259.

Siwak-Tapp CT, Head E, Muggenburg BA, Milgram NW, Cotman CW (2008) Region specific neuron loss in the aged canine hippocampus is reduced by enrichment. Neurobiol Aging 29:39-50.

Skoumalova A, Rofina J, Schwippelova Z, Gruys E, Wilhelm J (2003) The role of free radicals in canine counterpart of senile dementia of the Alzheimer type. Exp Gerontol 38:711-719.

Sung S, Yao Y, Uryu K, Yang H, Lee VM, Trojanowski JQ, Pratico D (2004) Early vitamin E supplementation in young but not aged mice reduces
Abeta levels and amyloid deposition in a transgenic model of Alzheimer's disease. FASEB J 18:323-325.

Tapp PD, Siwak CT, Estrada J, Head E, Muggenburg BA, Cotman CW, Milgram NW (2003) Size and reversal learning in the beagle dog as a measure of executive function and inhibitory control in aging. Learn Mem 10:64-73.

Tapp PD, Siwak CT, Gao FQ, Chiou JY, Black SE, Head E, Muggenburg BA, Cotman CW, Milgram NW, Su MY (2004) Frontal lobe volume, function, and beta-amyloid pathology in a canine model of aging. J Neurosci 24:8205-8213.

van Praag H, Lucero MJ, Yeo GW, Stecker K, Heivand N, Zhao C, Yip E, Afanador M, Schroeter H, Hammerstone J, Gage FH (2007) Plantderived flavanol $(-)$ epicatechin enhances angiogenesis and retention of spatial memory in mice. J Neurosci 27:5869-5878.

Wang J, Ho L, Zhao W, Ono K, Rosensweig C, Chen L, Humala N, Teplow DB, Pasinetti GM (2008) Grape-derived polyphenolics prevent Abeta oligomerization and attenuate cognitive deterioration in a mouse model of Alzheimer's disease. J Neurosci 28:6388-6392.

Willis SL, Tennstedt SL, Marsiske M, Ball K, Elias J, Koepke KM, Morris JN, Rebok GW, Unverzagt FW, Stoddard AM, Wright E (2006) Long-term effects of cognitive training on everyday functional outcomes in older adults. JAMA 296:2805-2814.

Wu A, Ying Z, Gomez-Pinilla F (2008) Docosahexaenoic acid dietary supplementation enhances the effects of exercise on synaptic plasticity and cognition. Neuroscience 155:751-759.

Zandi PP, Anthony JC, Khachaturian AS, Stone SV, Gustafson D, Tschanz JT, Norton MC, Welsh-Bohmer KA, Breitner JC (2004) Reduced risk of Alzheimer disease in users of antioxidant vitamin supplements: the Cache County Study. Arch Neurol 61:82-88.

Zeger S, Liang KY (1986) Longitudinal data analysis for discrete and continuous outcomes. Biometrics 42:121-130. 